\title{
Interactions of micelles with fluorescence-labeled polyelectrolytes
}

\author{
Yotaro Morishima ${ }^{\mathrm{a}, *}$, Masanobu Mizusaki a, Katsunori Yoshida ${ }^{\mathrm{b}}$, \\ Paul L. Dubin ${ }^{\mathrm{b}}$ \\ a Department of Macromolecular Science, Osaka University, Toyonaka, Osaka 560-0043, Japan \\ ${ }^{\mathrm{b}}$ Department of Chemistry, Indiana-Purdue University, I, Indianapolis, IN 46202, USA
}

\begin{abstract}
Pyrene-labeled polyelectrolytes can be used to study the interaction between the polyelectrolyte and an oppositely charged micelle, if the micelle incorporates a fluorescence quencher. If the charge on the micelle is varied systematically, polymer-micelle complex formation can be observed at some well-defined micelle surface charge density. Applying a kinetic model to steady-state and time-dependent fluorescence quenching data, one can estimate the binding constant $(K)$, association rate constant, and lifetime (residence time). $K$ increases strongly with increase in micelle surface charge density $(\sigma)$ or decrease in ionic strength $(\mu)$. These effects arise from the dependence of association rate constant and residence time on $\sigma$ and $\mu$. While these observations reflect the fundamental electrostatic nature of the interaction, it is also found that micelles preferentially bind to pyrene sites, so that complex formation results from the conjoint action of electrostatic and hydrophobic forces. (C) 1999 Elsevier Science B.V. All rights reserved.
\end{abstract}

Keywords: Pyrene-labeled polyelectrolytes; Polymer-micelle interactions; Fluorescence quenching; Kinetic analysis; Binding constants

\section{Introduction}

The interaction of macroions with oppositely charged colloidal particles is an important phenomenon in biological systems, such as the nonspecific association of DNA with basic proteins [1], immobilization of enzymes in polyelectrolyte complexes [2], and purification of proteins by selective precipitation and coacervation [3]. Macroion-colloid interactions are also important

\footnotetext{
* Corresponding author.
}

in commercial processes which include water treatment by colloidal flocculation [4], flocculation of cellulose fibers in paper making [5], recovery of mineral suspensions [6], precipitation of bacterial cells [7], and the stabilization of concentrated preceramic suspensions [8]. Polyelectrolyte-micelle systems may provide models for such interactions.

Most of the experimental papers on polymersurfactant interactions in the past two decades [9-12] have dealt either with interactions between polyelectrolytes and oppositely charged surfactant 
monomers, or with the association of nonionic polymers with ionic surfactant micelles. In the former case electrostatic forces dominate the interaction, although hydrophobic forces may play a secondary role [13-15]. The best known example of the latter case is probably the system involving poly(ethylene oxide) (PEO) and sodium dodecyl sulfate (SDS) micelles [16-20].

Polyelectrolytes interact with oppositely charged surfactant micelles so strongly that irreversible macroscopic phase separation usually occurs. This at one time inhibited studies on polyelectrolytes with oppositely charged surfactant micelles. Dubin et al. [21-25] showed that such strong electrostatic interactions could be attenuated by 'diluting' the surface charge of ionic surfactant micelles with nonionic surfactants leading to the formation of soluble polyelectrolytemicelle complexes [21-30]. In these systems, complex formation occurs abruptly when the micellar surface charge density $(\sigma)$ reaches a certain critical level, and the magnitude of this value varies directly with the ionic strength $(\mu)$ and inversely with the polymer linear charge density $(\xi)$. Values of $\sigma$ may be adjusted experimentally in ionic/nonionic mixed micelles via the mole fraction of ionic surfactant, i.e. $Y$. Many studies demonstrate that $Y_{\mathrm{c}}$, a critical value corresponding to the onset of complex formation, varies linearly with $\mu^{1 / 2}$. Since the Debye length $\left(\kappa^{-1}\right)$ varies as $\mu^{-1 / 2}$, this dependence suggests that the interaction is predominantly controlled by an electrostatic force. This experimental observation is consistent with results of theoretical approaches applied to the adsorption of polyelectrolytes to charged surfaces or micelles [31-34], i.e. the interaction resembles a phase transition and the interaction energy increases with $\sigma(\propto Y), \xi$, and $\kappa^{-1}$ $\left(\propto \mu^{-1 / 2}\right)$.

Many experimental approaches have been used to study polymer-surfactant interactions such as turbidimetry [21,23], light scattering [26-30], small-angle neutron scattering [35], electrophoretic light scattering [36,37], NMR [38], dialysis [26,39,40], surface tension [41-44], viscometry [28,41], calorimetry [45], dye-solubilization [46,47], and solvatochromic studies [48], but relatively few techniques can be utilized to iden- tify the phase transition and to clarify the dynamics of polyelectrolyte-micelle association. Static $[28,30,49]$ and quasielastic [25,27-29,49] light scattering especially have provided important information on the size and structure of polymermicelle complexes but soluble complexes can only be detected by QELS if their lifetime (residence time) is sufficiently long and the scattering intensity of the complexes is sufficiently large compared with those of the micelles and polymers from which they form.

Fluorescence methods have been increasingly employed to examine polymer-surfactant interactions partly because of their inherent sensitivity, although they have not yet been used to study the phase transition and dynamics of polyelectrolytemicelle systems. In general, for the study of polymer-surfactant systems, fluorophores have been used in two ways. In the first case, monomeric fluorophores such as pyrene are used as fluorescence probes. For example, pyrene has been used to measure the critical aggregation concentration (CAC) for poly(styrene sulfonate) (PSS)/dodecyltrimethylammonium bromide (DTAB), through fluorescence quenching [50], the ratio of the third to first vibrational fine structure in pyrene fluorescence spectra $\left(I_{3} / I_{1}\right)$ [51], and timedependent fluorescence [50,51]. In the second case, the fluorophore is covalently bound to the polymer chain. Winnik et al. studied the interactions of pyrene-labeled hydroxypropylcellulose (PyHPC) [52] and PEO (PyPEO) [53] with SDS. Both excimer/monomer emission intensity ratio $\left(I_{\mathrm{E}} / I_{\mathrm{M}}\right)$ and $I_{3} / I_{1}$ indicate that these polymers associate with surfactants and form polymer-surfactant complexes below the critical micelle concentration (CMC). In a related study, we examined the binding of a protein to a pyrene-labeled polyelectrolyte by focusing on pyrene fluorescence which was enhanced by the nonradiative energy transfer from singlet-excited tryptophan residues in lysozyme to pyrene labels [54]

More recently, we studied the quenching of a pyrene-labeled polyanion arising from its interaction with cationic micelles in which a quencher was solubilized [55]. The intensity of the polyelectrolyte-micelle interaction is modulated in two ways: by controlling the ratio of cationic/nonionic 
surfactants in the micelle (i.e. $\sigma$ ) and by controlling the ionic strength (i.e. $\kappa^{-1}$ ). The enhancement of quenching upon increase in $\sigma$ or $\kappa^{-1}$ was investigated by steady-state and time-dependent fluorescence spectroscopy to provide insight into the dynamics of polyelectrolyte-micelle association.

In this article, we will focus on the interactions of poly(sodium 2-(acrylamido)-2-methylpropanesulfonate) (PAMPS) with mixed micelles of $n$-dodecyl hexa(oxyethylene) glycol monoether $\left(\mathrm{C}_{12} \mathrm{E}_{6}\right)$ and cetyltrimethylammonium chloride (CTAC). We will discuss the dynamics and kinetics of the polymer-micelle complex formation based on fluorescence quenching studies by use of pyrenelabeled PAMPS (PyPAMPS) (scheme I) and quencher-solubilized $\mathrm{C}_{12} \mathrm{E}_{6} / \mathrm{CTAC}$ mixed micelles. We will also discuss a hydrophobic influence of the label in PyPAMPS on the polymer-micelle interactions [55].

\section{Polyanions with and without fluorescence-labels}

PyPAMPS was prepared by copolymerization of 2-(acrylamido)-2-methylpropanesulfonic acid (AMPS) and $N$-(1-pyrenylmethyl)methacryamide [56]. The content of the pyrene unit in the copolymers was limited to 0.5 or $1 \mathrm{~mol} \%$, which was determined by UV absorbance at $343 \mathrm{~nm}$. This low mole percent of pyrene in the polymer assures one that isolated pyrene chromophores exist and that alterations of the polyelectrolyte properties are minimized. The molecular weights (MW) of the pyrene-labeled polymer were estimated to be $1.1 \times 10^{5}$ and $4 \times 10^{4}$ for polymers with 0.5 and 1 $\mathrm{mol} \%$ pyrene contents, respectively. For turbidimetric and QELS studies, a homopolymer of AMPS (PAMPS) without pyrene labeled (MW = $1.0 \times 10^{6}$ ) was also employed (Scheme 1$)$.

\section{Absorption and fluorescence spectra}

Electronic absorption and emission spectra of some aromatic compounds are sensitive to the polarity of media, and therefore they can be utilized as micropolarity probes [57-60].

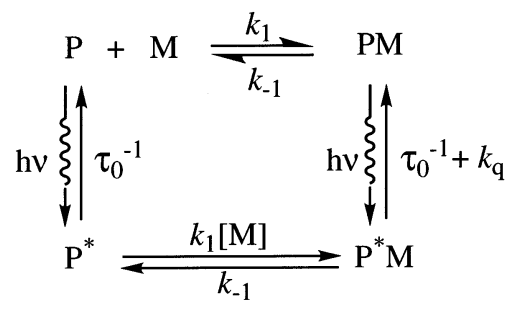

Scheme 1.

Absorption maxima $\left(\lambda_{\max }\right)$ for the $0-0$ band of pyrene in PyPAMPS ( $1 \mathrm{~mol} \%$ pyrene) are plotted as a function of $Y\left(=[\mathrm{CTAC}] /\left\{\left[\mathrm{C}_{12} \mathrm{E}_{6}\right]+\right.\right.$ [CTAC] $\}$ ) at $\mu=0.2$ in Fig. 1. While the absorption spectra are identical at $0<Y<0.04$, they show an increasing red shift at $Y>0.05$ and reach a maximum red shift at $Y>0.11$. The $I_{3} / I_{1}$, ratio of the pyrene fluorescence is sensitive to the environmental polarity [61]. It is generally known that the $I_{3} / I_{1}$ ratio is larger in less polar media. In a manner similar to the behavior of $\lambda_{\max }$, the $I_{3} / I_{1}$ ratios are constant at $Y<0.04$ but decrease in the region $0.05<Y<0.10$ and level off at $Y>0.11$. The $Y$ value at which the red shift in $\lambda_{\max }$ and the decrease in the $I_{3} / I_{1}$ ratio commence corresponds to $Y$ at which strong quenching of pyrene fluorescence begins to occur, as will be discussed later.

In a control experiment, absorption and fluorescence spectra of PyPAMPS were measured in mixtures of water and poly(ethylene glycol)

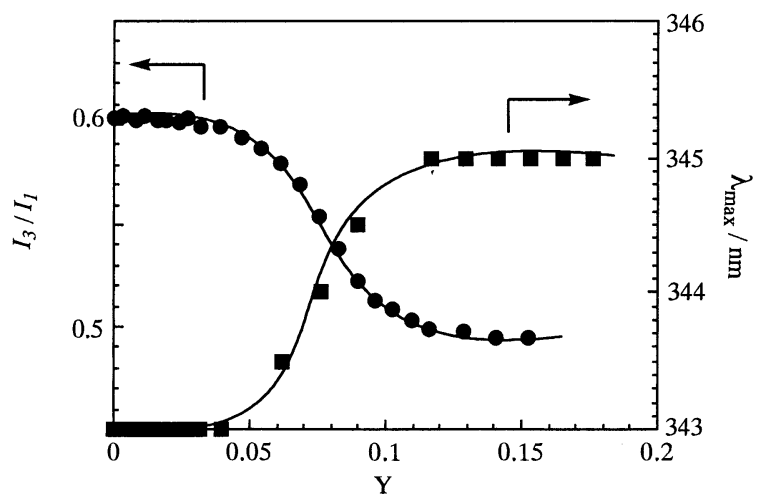

Fig. 1. $I_{3} / I_{1}$ and $\lambda_{\max }$ plotted as a function of $Y$ for PyPAMPS ( $1 \mathrm{~mol} \%$ pyrene) in the presence of $\mathrm{C}_{12} \mathrm{E}_{6} / \mathrm{CTAC}$ micelles: $[$ PyPAMPS $]=0.05 \mathrm{~g} \mathrm{l}^{-1},\left[\mathrm{C}_{12} \mathrm{E}_{6}\right]=30 \mathrm{mM}$, and $[\mathrm{NaCl}]=0.2$ M. 


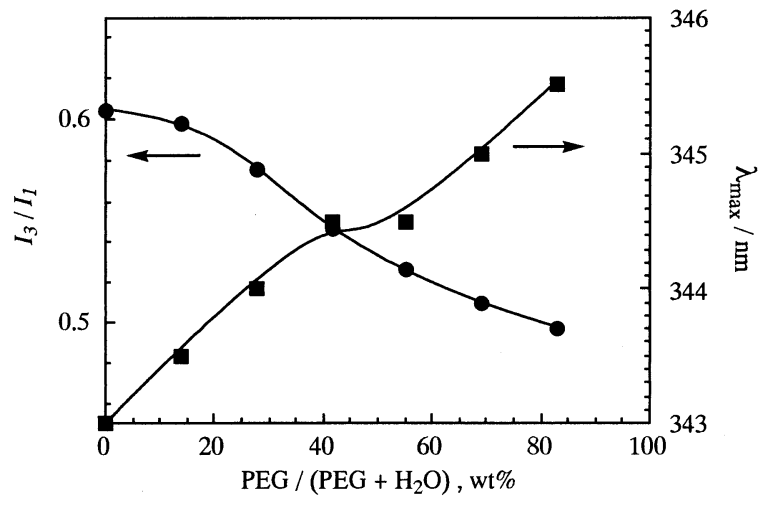

Fig. 2. $I_{3} / I_{1}$ and $\lambda_{\max }$ for PyPAMPS ( $1 \mathrm{~mol} \%$ pyrene) plotted as a function of the wt.\% of PEG in the mixture of PEG and water.

(PEG) $\quad(\mathrm{MW} \cong 500)$ at varying compositions (Fig. 2). As the weight fraction of PEG is increased, the $I_{3} / I_{1}$ ratio decreases while $\lambda_{\max }$ for the pyrene $0-0$ absorption band increases. These observations indicate that the pyrene labels are incorporated into the hexa(ethylene oxide) palisade layer in the $\mathrm{C}_{12} \mathrm{E}_{6} / \mathrm{CTAC}$ mixed micelle when complexes are formed. It should be noted that, when low molecular weight pyrene itself is solubilized in the $\mathrm{C}_{12} \mathrm{E}_{6}$ micelle, pyrene resides in the hydrophobic core of the micelle; the $I_{3} / I_{1}$ ratio for pyrene solubilized in the $\mathrm{C}_{12} \mathrm{E}_{6}$ micelle is 0.893 while it is 0.573 for pyrene in pure water. This difference between the polymerbound pyrene and free pyrene indicates that the pyrene labels in PyPAMPS are prevented from penetrating into the hydrophobic core of the micelle by constraint exerted by the polymer chain.

\section{Fluorescence quenching}

Pyrene fluorescence is known to be quenched by cetylpyridinium chloride (CPC) [62]. Fig. 3 compares Stern-Volmer plots for quenching of PyPAMPS ( $1 \mathrm{~mol} \%$ pyrene) fluorescence by CPC in the absence and presence of varying concentrations of $\mathrm{C}_{12} \mathrm{E}_{6}$ at $\mu=0.2$. Here, $I_{0}$ and $I$ are the steady-state fluorescence intensities in the absence and presence of CPC. The high efficiency of the cationic quencher $\mathrm{CPC}$, in the absence of $\mathrm{C}_{12} \mathrm{E}_{6}$, is attributed to its electrostatic binding to the polyanion. Evidence for static quenching by CPC are: (1) the steady-state quenching data follow Perrin kinetics; (2) the fluorescence lifetimes are practically independent of the CPC concentration; and (3) the peak counts in single-photon counting measurements of fluorescence decays decrease with an increase in the CPC concentration. However, in the presence of micellar $\mathrm{C}_{12} \mathrm{E}_{6}(\mathrm{CMC}$ for $\mathrm{C}_{12} \mathrm{E}_{6}$ is $0.06 \mathrm{mM}$ at $20^{\circ} \mathrm{C}$ [63]), the quenching is remarkably suppressed. This indicates that CPC molecules are solubilized in $\mathrm{C}_{12} \mathrm{E}_{6}$ micelles and direct interaction with PyPAMPS is prevented. As the concentration of $\mathrm{C}_{12} \mathrm{E}_{6}$ decreases, the molar ratio $\mathrm{CPC} / \mathrm{C}_{12} \mathrm{E}_{6}$ increases, and the positive charge density of the CPC-carrying micelle increases, allowing the micelle to interact electrostatically with the polyanion. Thus, significant quenching is observed for $[\mathrm{CPC}] \cong 0.8 \mathrm{mM}$ in the presence of $10 \mathrm{mM} \mathrm{C}{ }_{12} \mathrm{E}_{6}$, corresponding to a cationic mole fraction of 0.075 , consistent with the $Y$ value required for substantial quenching in the CTAC $/ \mathrm{C}_{12} \mathrm{E}_{6}$ system (see below).

The micelle charge density can be continuously increased by a 'type I' titration [20-25,49] which involves the addition of CTAC to the CPC-carrying $\mathrm{C}_{12} \mathrm{E}_{6}$ micelle. Fig. 4 compares fluorescence spectra and fluorescence decays of PyPAMPS (1 $\mathrm{mol}^{\%}$ pyrene) in the presence of $30 \mathrm{mM} \mathrm{C}{ }_{12} \mathrm{E}_{6}$ at $\mu=0.2$ with and without $0.5 \mathrm{mM} \mathrm{CPC}$ at varying $Y$, where $Y=\{[\mathrm{CTAC}]+[\mathrm{CPC}]\} /\left\{\left[\mathrm{C}_{12} \mathrm{E}_{6}\right]+\right.$

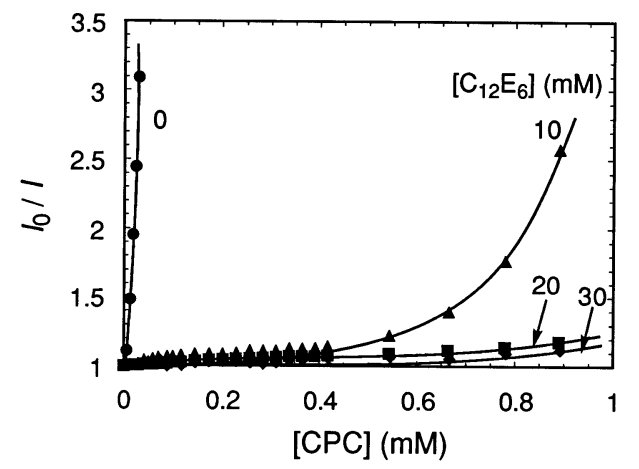

Fig. 3. Stern-Volmer plots for fluorescence quenching of PyPAMPS ( $1 \mathrm{~mol} \%$ pyrene) by CPC in the absence and presence of varying concentrations of $\mathrm{C}_{12} \mathrm{E}_{6}$ in $0.2 \mathrm{M} \mathrm{NaCl}$ aqueous solution. 

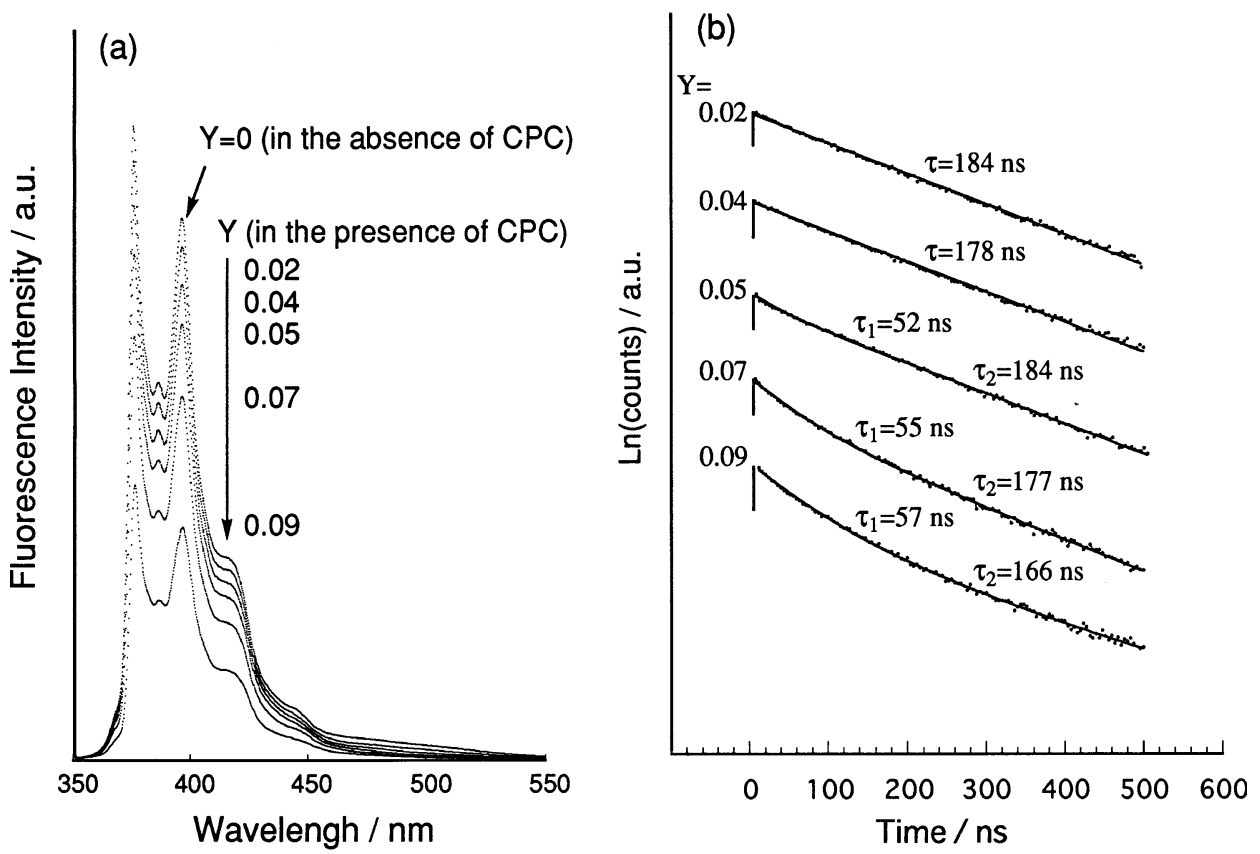

Fig. 4. Steady-state fluorescence spectra (a) and fluorescence decay profiles (b) for PyPAMPS (1 mol\% pyrene) at varying $Y$ in the absence and presence of CPC-carrying $\mathrm{C}_{12} \mathrm{E}_{6} / \mathrm{CTAC}$ mixed micelles: [PyPAMPS] $=0.05 \mathrm{~g}^{-1},\left[\mathrm{C}_{12} \mathrm{E}_{6}\right]=30 \mathrm{mM},[\mathrm{CPC}]=0.5 \mathrm{mM}$, and $[\mathrm{NaCl}]=0.2 \mathrm{M}$.

$[\mathrm{CTAC}]+[\mathrm{CPC}]\}$. Under these conditions, the contribution of CPC to $Y$ is 0.016 , and the average number of CPC per micelle $(n)$ is five if the aggregation number of $\mathrm{C}_{12} \mathrm{E}_{6}$ is assumed to be $3 \times 10^{2}$ [63]. When $Y<0.04$, the fluorescence is only slightly quenched and the decays are single exponential. This slight quenching is dynamic and arises from collision of CPC-carrying micelles with pyrene sites in PyPAMPS. These observations, taken together with the results in Fig. 3, indicate that essentially all CPC molecules are incorporated into the micelles and no free CPC remains in the bulk water phase. At $Y \cong 0.05$, however, fluorescence quenching begins to increase significantly with increasing $Y$, and the decays become double-exponential with a shorter lifetime component on the order of $50 \mathrm{~ns}$. The lifetime of the longer-lived component progressively shortens as $Y$ is increased while that of the shorter-lived component does not change much.

Normalized fluorescence intensities, $I / I_{0}$, are plotted in Fig. 5 as a function of $Y$ at $\mu=0.1,0.2$, and 0.3 , where $I$ is the fluorescence intensity of
PyPAMPS in the presence of the CPC-carrying $\mathrm{C}_{12} \mathrm{E}_{6} / \mathrm{CTAC}$ at varying $Y$, and $I_{0}$ is the fluorescence intensity in the presence of CPC-free micelles at $Y=0$. Regions of $Y$ in which strong quenching occurs depend on the ionic strength; $0.025<Y<0.065,0.05<Y<0.11$, and $0.09<$

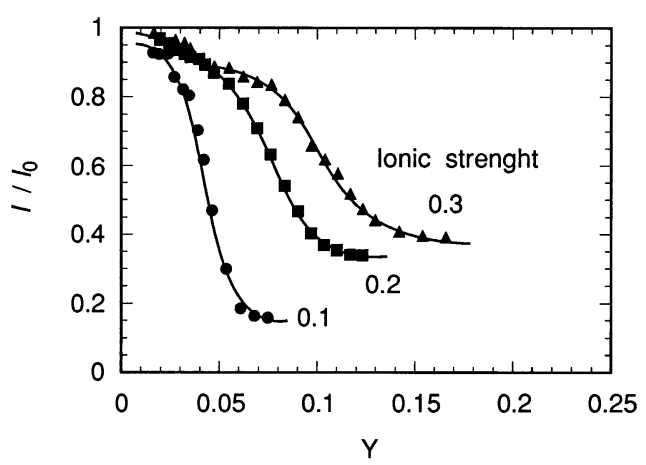

Fig. 5. Normalized fluorescence intensity for PyPAMPS (1 mol\% pyrene) as a function of $Y$ in the presence of $\mathrm{C}_{12} \mathrm{E}_{6} /$ CTAC mixed micelles at varying ionic strengths: [PyPAMPS $]=0.05 \mathrm{~g} \mathrm{l}^{-1},\left[\mathrm{C}_{12} \mathrm{E}_{6}\right]=30 \mathrm{mM}$, and $[\mathrm{CPC}]=0.5$ $\mathrm{mM}$. 
$Y<0.16$ at $\mu=0.1,0.2$ and 0.3 , respectively. These observations provide evidence of the binding between PyPAMPS and CPC-carrying micelle. The regime of strong quenching is observed to be initiated at $Y$ which is in agreement with the onset of turbidity and scattering intensity, as will be discussed later.

\section{Kinetic model for fluorescence quenching}

To interpret the fluorescence quenching data, a kinetic model based on an association equilibrium for the CPC-carrying $\mathrm{C}_{12} \mathrm{E}_{6} / \mathrm{CTAC}$ mixed micelle and the pyrene-labeled polymer has been proposed (Scheme 1).

Here, $\mathrm{P}$ denotes the pyrene label in the polymer, $\mathrm{M}$ the quencher-carrying mixed micelle, $\mathrm{PM}$ the complex between $\mathrm{P}$ and $\mathrm{M}, k_{1}$ and $k_{-1}$ the association and dissociation rate constants, respectively, $\tau_{0}$ the fluorescence lifetime of pyrene in the absence of quencher, and $k_{\mathrm{q}}$ the first-order quenching rate constant within the complex. At equilibrium, the concentration of the complex is given by

$[\mathrm{PM}]=K[\mathrm{P}][\mathrm{M}]$

where $K$ is the association equilibrium constant (binding constant), i.e. $K=k_{1} / k_{-1}$.

When UV light is irradiated at equilibrium, both the free (uncomplexed) and complexed pyrenes are photoexcited. Fluorescence quenching occurs within the complex but photoexcited free pyrene $\left(\mathrm{P}^{*}\right)$ can encounter a quencher-carrying mixed micelle within its lifetime and can form a complex $\left(\mathrm{P}^{*} \mathrm{M}\right)$ with a rate constant $k_{1}$.

Assuming that the rate of deactivation of singlet-excited pyrene in the complex is much faster than the rate of dissociation of the complex, i.e. $\tau_{0}^{-1}+k_{\mathrm{q}} \gg k_{-1}$, one can derive the rate equations for $\left[\mathrm{P}^{*}\right]$ and $\left[\mathrm{P}^{*} \mathrm{M}\right]$ under transient conditions with excitation at time $t=0$ by a light pulse of negligible duration;

$$
\begin{aligned}
& \mathrm{d}\left[\mathrm{P}^{*}\right]_{t} / \mathrm{d} t=-\left(\tau_{0}^{-1}+k_{1}[\mathrm{M}]\right)\left[\mathrm{P}^{*}\right]_{t} \\
& \mathrm{~d}\left[\mathrm{P}^{*} \mathrm{M}\right]_{t} / \mathrm{d} t=-\left(\tau_{0}^{-1}+k_{\mathrm{q}}\right)\left[\mathrm{P}^{*} \mathrm{M}\right]_{t}+k_{1}\left[\mathrm{P}^{*}\right]_{t}[\mathrm{M}]
\end{aligned}
$$

Solving Eqs. (2) and (3) applying the initial condition, $\left[\mathrm{P}^{*}\right]=\left[\mathrm{P}^{*}\right]_{t=0}$ and $\left[\mathrm{P}^{*} \mathrm{M}\right]=\left[\mathrm{P}^{*} \mathrm{M}\right]_{t=0}$ at $t=0$, the total concentrations of the photoexcited free and complexed pyrene sites at time $t$ are given by

$\left[\mathrm{P}^{*}\right]_{t}+\left[\mathrm{P}^{*} \mathrm{M}\right]_{t}=A \exp \left(-t / \tau_{1}\right)+B \exp \left(-t / \tau_{2}\right)$

where

$$
\begin{aligned}
& A=\left[\mathrm{P}^{*} \mathrm{M}\right]_{t=0}\left\{1-k_{-1} /\left(k_{\mathrm{q}}-k_{1}[\mathrm{M}]\right)\right\} \\
& B=\left[\mathrm{P}^{*}\right]_{t=0}\left\{k_{\mathrm{q}} /\left(k_{\mathrm{q}}-k_{1}[\mathrm{M}]\right)\right\} \\
& \left(1 / \tau_{1}\right)=\left(1 / \tau_{0}\right)+k_{\mathrm{q}}
\end{aligned}
$$

and

$\left(1 / \tau_{2}\right)=\left(1 / \tau_{0}\right)+k_{1}[\mathrm{M}]$

On the other hand, under steady-state conditions, the rate equations are given by

$$
\begin{aligned}
& \mathrm{d}\left[\mathrm{P}^{*}\right]_{t} / \mathrm{d} t=\{[\mathrm{P}] /([\mathrm{P}]+[\mathrm{PM}])\} I_{\mathrm{a}} \\
&-\left(\tau_{0}^{-1}+k_{1}[\mathrm{M}]\right)\left[\mathrm{P}^{*}\right]_{t} \\
& \mathrm{~d}\left[\mathrm{P}^{*} \mathrm{M}\right]_{t} / \mathrm{d} t=\{[\mathrm{PM}] /([\mathrm{P}]+[\mathrm{PM}])\} I_{\mathrm{a}}+k_{1}[\mathrm{M}]\left[\mathrm{P}^{*}\right]_{t} \\
&-\left(\tau_{0}^{-1}+k_{\mathrm{q}}\right)\left[\mathrm{P}^{*} \mathrm{M}\right]_{t}
\end{aligned}
$$

where $I_{\mathrm{a}}$ is the rate of light absorption. Under steady-state conditions, $\mathrm{d}\left[\mathrm{P}^{*}\right]_{t} / \mathrm{d} t=0$ and $\mathrm{d}\left[\mathrm{P}^{*} \mathrm{M}\right]_{t} / \mathrm{d} t=0$. Thus the total steady-state concentrations of excited pyrenes are

$$
\begin{aligned}
{\left[\mathrm{P}^{*}\right]_{s}+\left[\mathrm{P}^{*} \mathrm{M}\right]_{s}=} & \{[\mathrm{P}] /([\mathrm{P}]+[\mathrm{PM}])\} \\
& \times I_{\mathrm{a}}\left\{(1+K[\mathrm{M}])\left(\tau_{0}^{-1}+k_{1}[\mathrm{M}]\right)\right. \\
& \left.+k_{\mathrm{q}}\right\} /\left\{\left(\tau_{0}^{-1}+k_{1}[\mathrm{M}]\right)\left(\tau_{0}^{-1}+k_{\mathrm{q}}\right)\right\}
\end{aligned}
$$

The ratio of fluorescence quantum efficiencies in the presence and absence of the quencher-carrying micelle is given by

$\Phi_{0} / \Phi=\tau_{1} / \tau_{0}+\left(\tau_{2} / \tau_{0}\right)\left\{1-\tau_{1} / \tau_{0}\right\}\{1 /(1+K[\mathrm{M}])\}$

By knowing the micelle concentration [M], one can calculate the binding constant $K$ from Eq. (12) by using steady-state fluorescence data $\left(\Phi_{0} / \Phi\right)$ and fluorescence decay data $\left(\tau_{0}, \tau_{1}\right.$, and $\left.\tau_{2}\right)$. The association rate constant $k_{1}$ and quenching rate constant $k_{\mathrm{q}}$ can be calculated from Eqs. (6) and 
(7), respectively, based on the fluorescence decay data. In turn, one can calculate the residence time $\left(1 / k_{-1}\right)$ of the polymer-micelle complex.

\section{Kinetic analysis of fluorescence quenching}

The association rate constants, residence times, and binding constants for the system containing PyPAMPS ( $1 \mathrm{~mol} \%$ pyrene) and CPC-carrying $\mathrm{C}_{12} \mathrm{E}_{6} / \mathrm{CTAC}$ micelle at $\mu=0.2$ were calculated from the steady-state and time-dependent fluorescence data (Fig. 4) on the basis of the kinetic model, and are plotted as a function of $Y$ in Fig. 6. The binding constant $K$ shows an increase of about one order of magnitude upon increasing $Y$ from 0.05 to 0.11 . The association rate constant $k_{1}$ increases by about one order of magnitude with

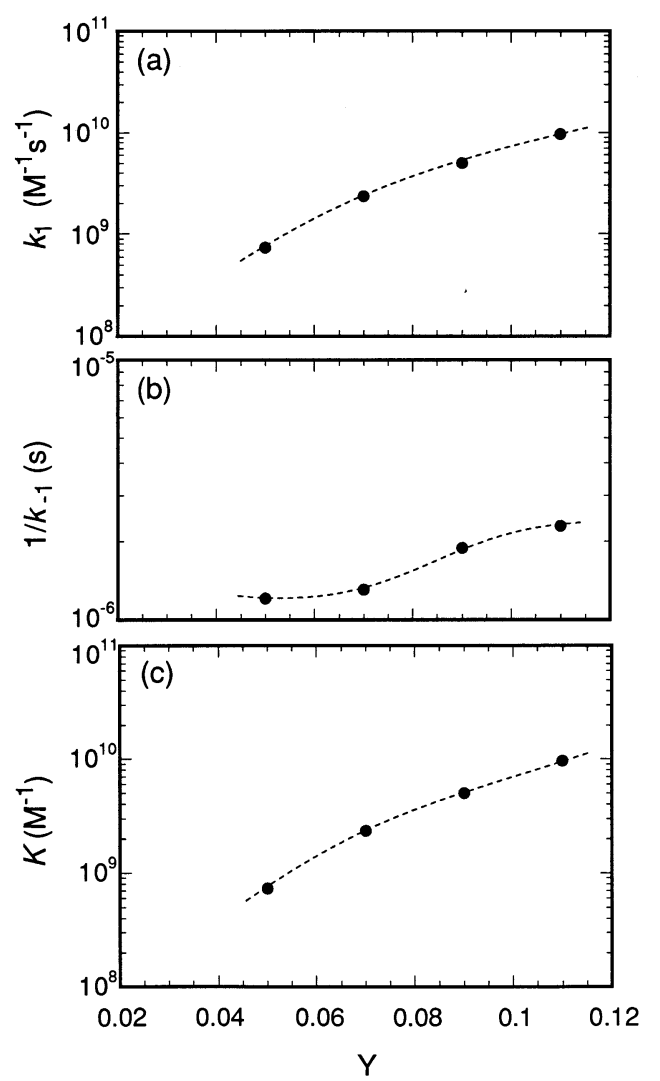

Fig. 6. The association rate constant (a) residence time (b) and biding constant (c) as a function of $Y$ for $0.05 \mathrm{~g}^{-1} \mathrm{Py}-$ PAMPS ( $1 \mathrm{~mol} \%$ pyrene) $+30 \mathrm{mM} \mathrm{C}_{12} \mathrm{E}_{6}$ in $0.2 \mathrm{M} \mathrm{NaCl}$.

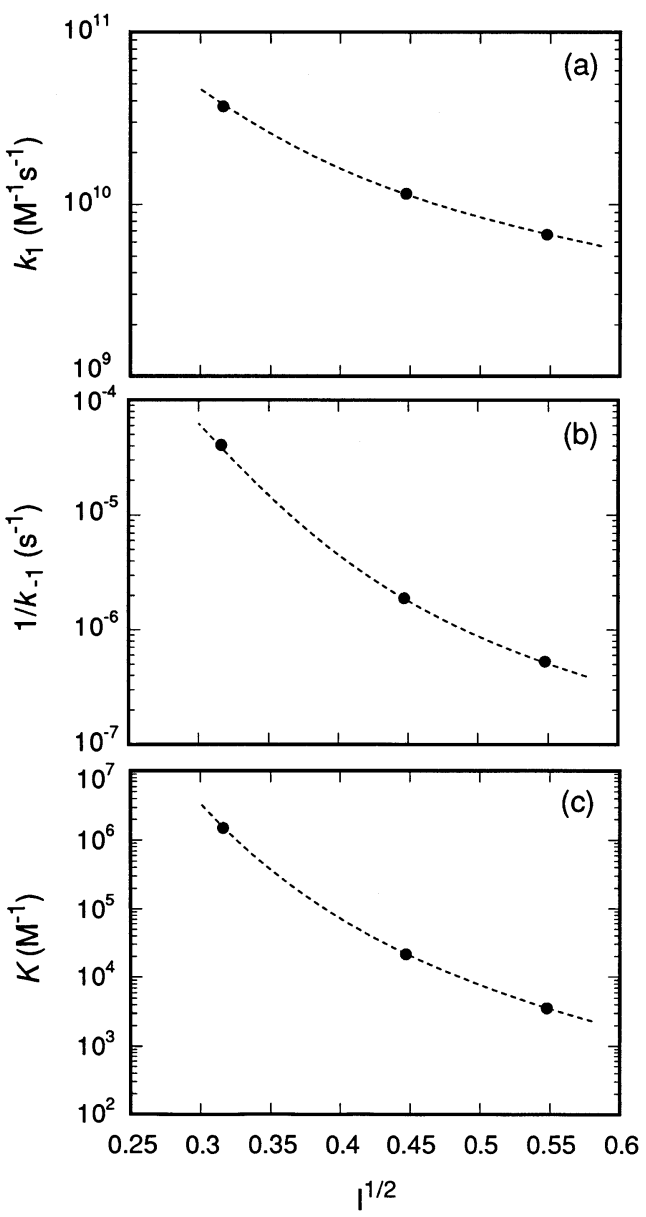

Fig. 7. The association rate constant (a) residence time (b) and biding constant (c) as a function of the square root of the ionic strength for $0.05 \mathrm{~g} \mathrm{l}^{-1}$ PyPAMPS ( $1 \mathrm{~mol} \%$ pyrene $)+30 \mathrm{mM}$ $\mathrm{C}_{12} \mathrm{E}_{6} / \mathrm{CTAC}$ at $Y=0.09+[\mathrm{CPC}]=0.5 \mathrm{mM}$.

increasing $Y$ from 0.05 to 0.11 while the residence time $1 / k_{-1}$ increases from about $1 \mu \mathrm{s}$ to $2.5 \mu \mathrm{s}$; i.e. the contribution of $k_{1}$ to the increase in $K$ is larger than that of $1 / k_{-1}$.

The dependencies of these kinetic parameters on the ionic strength is shown in Fig. 7 as plots of $k_{1}, 1 / k_{-1}$, and $K$, against $\mu^{1 / 2}$ at $Y=0.09$. The binding between PyPAMPS and the micelle strongly depends on the ionic strength; $K$ decreasing by nearly three orders of magnitude upon increasing $\mu$ from 0.1 to 0.3 . This large change in the binding constant arises mainly from a large change in the residence time at varying ionic 
strengths. The residence time at $\mu=0.1$ is $\sim 50 \mu \mathrm{s}$ while it decreases to $\sim 500 \mathrm{~ns}$ at $\mu=0.3$. The association rate constant shows a smaller decrease, less than one order of magnitude, in the region $0.1<\mu<0.3$.

\section{Hydrophobic perturbation of fluorescence labels}

In general, a potential problem in making use of fluorescence-labeled polyelectrolytes is a possibility of perturbation by the label. In fact, pyrenelabeled poly(ethylene oxide) [53] behaves as a hydrophobically-modified polymer even if the mole fraction of pyrene is small ( $\cong 1 \mathrm{~mol} \%)$, and the pyrene label enhances the hydrophobic association with micelles. Other studies [64-67] have also shown that hydrophobic modifications strengthen the polymer-surfactant interaction by providing hydrophobic sites to which surfactants bind preferentially.

For the interaction of PyPAMPS with mixed micelles of $\mathrm{C}_{12} \mathrm{E}_{6} / \mathrm{CTAC}$, turbidimetric, light scattering, and fluorescence studies revealed that, while the binding was predominantly driven by electrostatic forces, micelles bind preferentially to pyrene sites, indicating an importance of a conjoint effect of hydrophobic and electrostatic forces on the polyion-micelle interaction.

Type I turbidimetric titration data for PAMPS and PyPAMPS $(0.5 \mathrm{~mol} \%$ pyrene $)$ at $\mu=0.3$ are compared in Fig. 8 [55]. For PAMPS (Fig. 8(a)), turbidity begins to increase at $Y=0.18$, and then an abrupt phase separation occurs. These observations agree with those of previous studies on a number of similar polyelectrolyte-mixed micelle systems [21-23,68,69]; two critical values of $Y$, one corresponding to the first appearance of turbidity in excess of that of the polymer-free solutions $\left(Y_{\mathrm{c}}\right)$, and the other to a more abrupt and dramatic turbidity change $\left(Y_{\mathrm{p}}\right)$, corresponding to the phase separation. For PyPAMPS (Fig. 8(b)), turbidity begins to increase gradually at $Y=0.11$ and then increases suddenly at $Y=0.18$ (the first appearance of turbidity is designated as $Y_{\mathrm{c} 1}$, and the point of increasing slope as $Y_{\mathrm{c} 2}$ ), while only the second transition is seen for PAMPS. Since $Y_{\mathrm{c} 2}^{\tau}$ is equal to $Y_{\mathrm{c}}$ of the pyrene-free PAMPS

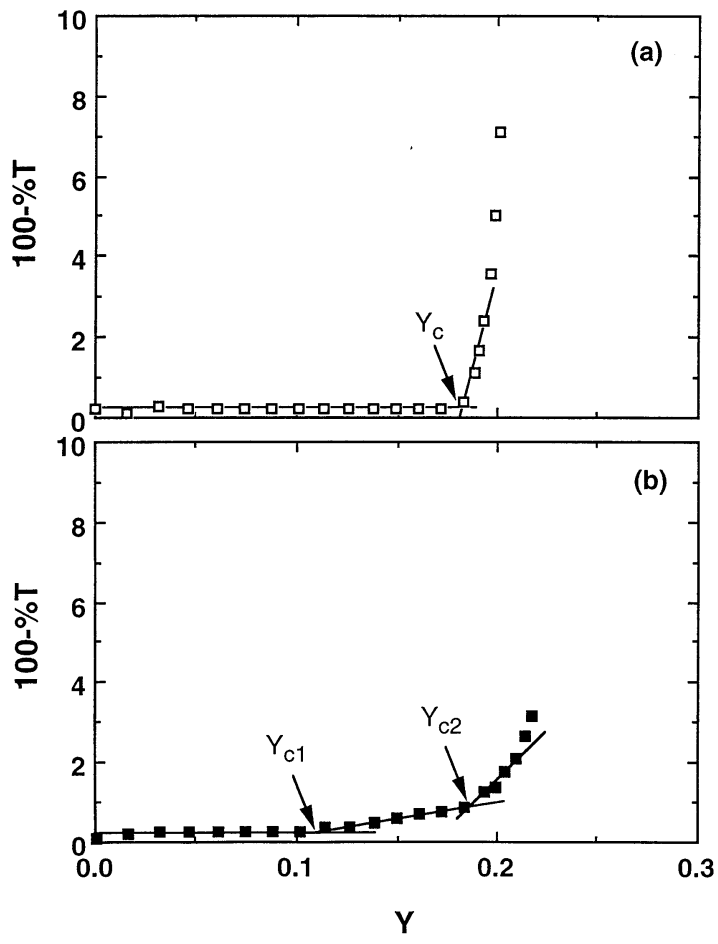

Fig. 8. Turbidimetric titrations of $0.5 \mathrm{~g}^{-1}$ PAMPS (a) and PyPAMPS (0.5 mol\% pyrene) (b) $+20 \mathrm{mM} \mathrm{C}_{12} \mathrm{E}_{6}$ titrated with $40 \mathrm{mM}$ CTAC in $0.3 \mathrm{M} \mathrm{NaCl}$.

system, it may correspond to the onset of polymer-micelle complex formation at sulfonate sites in PAMPS. On the other hand, $Y_{\mathrm{c} 1}$ at 0.11 , which is observed only for PyPAMPS, is presumably caused by complex formation between pyrenesites and micelles.

Photon count rate in thousands per second in QELS measurements on $0.5 \mathrm{~g}^{-1}$ PAMPS or PyPAMPS $(0.5 \mathrm{~mol} \%$ pyrene $)+20 \mathrm{mM} \mathrm{C}_{12} \mathrm{E}_{6}$ titrated with $40 \mathrm{mM} \mathrm{CTAC}$ at $\mu=0.3$ are plotted in Fig. 9 [55]. The data of the polymer-free micelle included for comparison show that the size of the mixed micelle changes with the mole fraction of the ionic surfactant [70]. In the presence of PAMPS, the intensities are identical to those for micelle alone bellow a critical $Y$, and increase abruptly at $Y=0.18$, corresponding to the onset of polymer-micelle interaction. The scattering intensities for PAMPS + micelle bellow $Y_{\mathrm{c}}$ are almost equal to those for polymer-free micelle. Even though the hydrodynamic radius $\left(R_{\mathrm{h}}\right)$ of 
PAMPS, $25 \mathrm{~nm}$, is twice as large as that of the micelle, 11-12 nm, scattering from PAMPS is not observed because of the large excess of micelles relative to polymer. The intensities for PyPAMPS + micelle coincide with those for micelle alone at $Y<0.10$, but the two diverge at $Y=0.10$, and abruptly separate at $Y=0.18$. Those critical values are in good agreement with turbidimetric titrations shown in Fig. 8(b). Since the increase of the scattering intensities for PyPAMPS + micelle is moderate at $Y_{\mathrm{c} 1}<Y<Y_{\mathrm{c} 2}$, a small primary complex of relatively low mass, which arises from the binding of micelles at polymeric pyrene-sites, is thought to form in this region. The results of size analysis indicate that the average $R_{\mathrm{h}}$ for PyPAMPS + micelle is $13 \mathrm{~nm}$ at $Y_{\mathrm{c} 1}<Y<Y_{\mathrm{c} 2}$, while $R_{\mathrm{h}}$ of PyPAMPS is $7.8 \mathrm{~nm}$ and that of micelles is $11-12 \mathrm{~nm}$. Since PyPAMPS $(0.5 \mathrm{~mol} \%$ pyrene) has on average only two pyrene-sites per polymer chain, and micelles may bind only to pyrene-sites of polymer at $Y_{\mathrm{c} 1}<Y<Y_{\mathrm{c} 2}$, it is reasonable to consider only intrapolymer primary complex formation in this region.

At $\mu=0.3$, a region of strong fluorescence quenching is observed at $0.09<Y<0.16$ (Fig. 5), which provides straightforward evidence of the binding between pyrene sites in PyPAMPS and CPC-carrying micelles [55]. The regime of strong quenching can be observed to be initiated at $Y=\sim 0.09$, which is fairly close to the onset of turbidity change in Fig. 8(b). Therefore, $Y_{\mathrm{c} 1}$ in

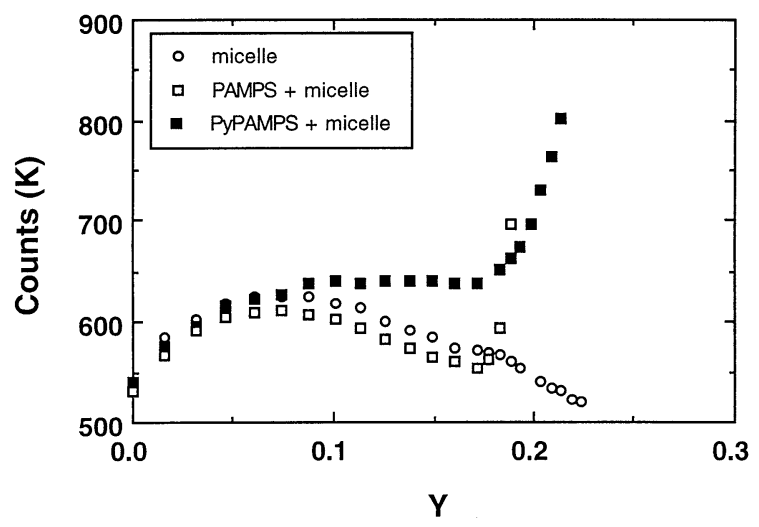

Fig. 9. Scattering intensity at $90^{\circ}$ for solutions of $0.5 \mathrm{~g} \mathrm{l}^{-1}$ PAMPS and PyPAMPS $(0.5 \mathrm{~mol} \%$ pyrene $)+20 \mathrm{mM} \mathrm{C}_{12} \mathrm{E}_{6}$ titrated with $40 \mathrm{mM} \mathrm{CTAC}$ in $0.3 \mathrm{M} \mathrm{NaCl}$.

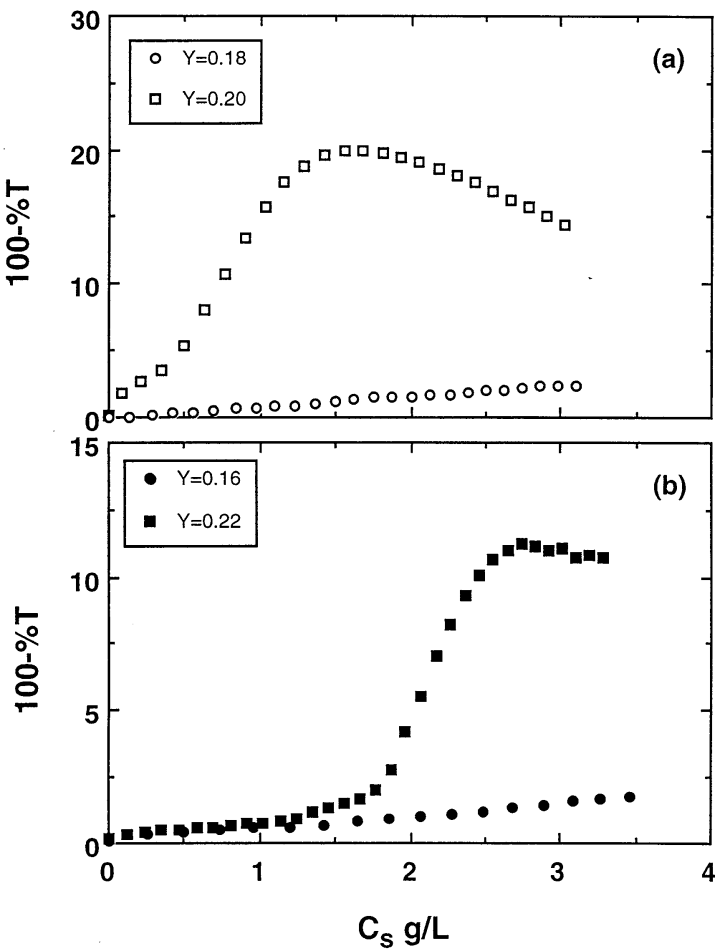

Fig. 10. Type II turbidimetric titrations of PAMPS (a) and PyPAMPS (0.5 mol\% pyrene) (b) in $0.3 \mathrm{M} \mathrm{NaCl}$ at varying $Y$.

Fig. 8(b) may correspond to the minimal $\sigma$ required to cause micelles to bind to the pyrene-sites in PyPAMPS. Since $Y_{\mathrm{c} 1}$ is smaller than $Y_{\mathrm{c} 2}$ by $50 \%$, it is suggested that the pyrene-label enhances the interaction; micelles need $50 \%$ less charge to bind to the pyrene sites than to the sulfonate sites. It is thus revealed that there is a conjoint effect of hydrophobic and electrostatic forces on the interaction between the pyrene-labeled PAMPS and $\mathrm{C}_{12} \mathrm{E}_{6} /$ CTAC mixed micelles.

Type II titrations [20-25,49] corresponding to the addition of mixed micelles at constant $Y$ to a polymer solution at constant $\mu$, also provide information about the stoichiometry of complex formation. Type II turbidimetric titrations were conducted at $0.1 \mathrm{~g}^{-1}$ PAMPS or PyPAMPS $(0.5$ mol $\%$ pyrene) $+\mathrm{C}_{12} \mathrm{E}_{6} / \mathrm{CTAC}$ mixed micelle at $\mu=0.3$ at constant $Y$, and the turbidity is plotted as a function of the total added surfactant $\left(C_{\mathrm{s}}\right)$ in Fig. 10 [55]. For PAMPS (Fig. 10(a)), the turbidity increases slightly with $C_{\mathrm{s}}$ at $Y=0.18\left(=Y_{\mathrm{c}}\right)$, 
while higher turbidity is observed at $Y=0.20$ $\left(>Y_{\mathrm{c}}\right.$ ), indicating formation of large interpolymer complexes. For PyPAMPS (Fig. 10(b)), the turbidity increases slightly at $Y=0.16\left(Y_{\mathrm{c} 1}<Y<\right.$ $Y_{\mathrm{c} 2}$ ) even though micelles are binding to the polymeric pyrene-sites, while a large increase of turbidity is observed at $Y=0.22\left(>Y_{\mathrm{c} 2}\right)$. It is noteworthy that turbidity begins to increase near $C_{\mathrm{s}}=0$ with increasing $C_{\mathrm{s}}$ for PAMPS, whereas it starts to increase (abruptly) only at $C_{\mathrm{s}}=1.6 \mathrm{~g} \mathrm{l}^{-1}$ for PyPAMPS. These findings are interpreted as follows. For PAMPS, micelles which have adequate surface charge density (at $Y>Y_{\mathrm{c}}$ ) to associate with the polyelectrolyte bind immediately when they are mixed with polymer, leading to large interpolymer complexes observed as high turbidity. For PyPAMPS, micelles initially bind to pyrene-sites even though they have enough surface charge density $\left(Y>Y_{\mathrm{c} 2}\right)$ to interact with sulfonate sites. Inasmuch as the resultant complex is intrapolymer, turbidity can not increase at low $C_{\mathrm{s}}$. After completion of binding to pyrene-sites, micelles start to associate with sulfonate sites consequently forming interpolymer complexes observed as high turbidity.

\section{Concluding remarks}

In this article we have attempted to demonstrate how fluorescence-labeled polyelectrolytes are useful to obtain information about the phasetransition-like behavior and dynamics of polymer-micelle interactions. Based on a kinetic model for polymer-micelle association, the binding constant, association rate constant, and residence time can be calculated from fluorescence quenching data with use of a pyrene-labeled polyanion and quencher-carrying nonionic/ cationic micelles. It was also revealed, however, that the pyrene-labeled polymer interacted with oppositely charged mixed micelles through conjoint hydrophobic and electrostatic forces. Although micelles associate preferentially with pyrene sites, the binding between these sites and micelles is strongly dominated by the electrostatic forces. Therefore, comparisons of these experimental results with those from theories and simu- lations may give rise to a further insight into polyelectrolyte-micelle interactions.

\section{References}

[1] (a) S.L. Shaner, P. Melancon, K.S. Lee, M.T. Burgess, M.T. Record Jr., Cold Spring Harbor Sump. Quant. Biol. 47 (1983) 463. (b) P.H. von Hippel, D.G. Bear, W.D. Morgan, J.A. McSwiggen, Ann. Rev. Biochem. 53 (1984) 389.

[2] (a) A. Margolin, S.F. Sherstyuk, V.A. Izumrudov, A.B. Zezin and V.A. Kabanov, Eur. J. Biochem. 146 (1985) 625. (b) S. Kohjiya, K. Maeda, Y. Ikushima, Y. Ishihara, S. Yamashita, Nippon Kagaku Kaishi, 12 (1985) 2302.

[3] P.L. Dubin, M.A. Strege, J. West, in: M. Ladisch (Ed.), Large Scale Protein Purification, American Chemical Society, Washington, DC, 1991.

[4] W.L.K. Schwoyer (Ed.), Polyelectrolytes for Water and Wastewater Treatment, CRC Press, Boca Raton, FL, 1981.

[5] L. Wågberg, L. Winter, L. Ödberg, T. Lindström, Colloids Surfaces 27 (1987) 163.

[6] A.D. Read, Br. Polym. J. 4 (1972) 253.

[7] N. Kawabata, T. Hayashi, M. Nishikawa, Bull. Chem. Soc. Jpn. 59 (1986) 2861.

[8] J. Cesarano III, I.A. Aksay, J. Am. Ceram. Soc. 71 (1988) 1062.

[9] Y. Li, P.L. Dubin, in: C.A. Herb, R.K. Prud'homme (Eds.), Structure and Flow in Surfactant Solutions, ACS Symposium Series 578 (ch. 23), American Chemical Society, Washington, DC 1994, 23, p. 320.

[10] E.D. Goddard, J. Am. Oil. Chem. Soc. 71 (1994) 1.

[11] Y.C. Wei, S.M. Hudson, J. Macromol. Sci.-Rev. Macromol. Chem. Phys. 35 (1995) 15.

[12] J.C. Brackman, J.B.F.N. Engberts, Chem. Soc. Rev. 22 (1993) 85.

[13] E.D. Goddard, Colloids Surfaces 19 (1986) 301.

[14] K. Hayakawa, J.C.T. Kwak, in: D.N. Rubingh, P.M. Holland (Eds.), Cationic Surfactants. Physical Chemistry (ch. 5), Marcel Dekker, New York, 1991, p. 189.

[15] B. Lindman, A. Khan, E. Marques, M. Miquel, L. Piculell, K. Thalberg, Pure Appl. Chem. 22 (1993) 85.

[16] R. Nagarajan, Colloids Surfaces 13 (1985) 1.

[17] R. Nagarajan, J. Chem. Phys. 90 (1989) 1980.

[18] E. Ruckenstein, G. Huber, H. Hoffmann, Langmuir 3 (1987) 382.

[19] J.C. François, J. Dayantis, J. Sabbadin, Eur. Polym. J. 43 (1985) 491.

[20] P.L. Dubin, J.H. Gruber, J. Xia, H. Zhang, J. Colloid Interface Sci. 148 (1992) 35.

[21] P.L. Dubin, D.R. Rigsbee, D.W. McQuigg, J. Colloid Interface Sci. 105 (1985) 509.

[22] D.W. McQuigg, J.I. Kaplan, P.L. Dubin, J. Phys. Chem. 96 (1992) 1973. 
[23] P.L. Dubin, R.J. Oteri, Colloid Interface Sci. 95 (1983) 453.

[24] P.L. Dubin, D.D. Davis, Macromolecules 17 (1984) 1294.

[25] P.L. Dubin, D.R. Rigsbee, L.M. Gan, M.A. Fallon, Macromolecules 21 (1988) 2555.

[26] J. Xia, P.L. Dubin, Y. Kim, J. Phys. Chem. 96 (1992) 6805.

[27] Y. Li, P.L. Dubin, H. Dautzenberg, U. Lück, J. Hartmann, Z. Tuzar, Macromolecules 28 (1995) 6795.

[28] Y. Li, J. Xia, P.L. Dubin, Macromolecules 27 (1994) 7049.

[29] Y. Li, P.L. Dubin, H.A. Havel, S.L. Edwards, H. Dautzenberg, Macromolecules 28 (1995) 3098.

[30] J. Xia, H. Zhang, D.R. Rigsbee, P.L. Dubin, T. Shaikh, Macromolecules 26 (1993) 2759.

[31] O.A. Evers, G.J. Fleer, J.M.H.M. Scheutjens, J.J. Lyklema, Colloid Interface Sci. 111 (1986) 446.

[32] M. Muthukumar, J. Chem. Phys. 86 (1987) 7230.

[33] T. Wallin, P. Linse, Langmuir 12 (1996) 305.

[34] T. Odijk, Langmuir 7 (1991) 1991.

[35] B. Cabane, R. Duplessix, J. Phys. (Paris) 43 (1982) 1529.

[36] B.R. Ware, D.D. Haas, in: R.I. Sha'afi, S.M. Fernadez (Eds.), Fast Methods in Physical Biochemistry and Cell Biology, Elsevier, Amsterdam, 1983.

[37] J. Xia, P.L. Dubin, T. Izumi, M. Hirata, E. Kokufuta, J. Polym. Sci. Polym. Phys. Ed. 34 (1996) 497.

[38] B. Cabane, J. Phys. Chem. 81 (1977) 1639.

[39] M.L. Fishman, F.R. Eirich, J. Phys. Chem. 75 (1971) 3135 .

[40] K. Shirahama, Colloid Polym. Sci. 252 (1974) 978.

[41] M.N. Jones, J. Colloid Interface Sci. 23 (1967) 36.

[42] M.J. Schwuger, J. Colloid Interface Sci. 43 (1973) 491.

[43] J.H. Buchingham, J. Lucassen, F. Hollway, J. Colloid Interface Sci. 67 (1978) 423.

[44] M. Murata, H. Arai, J. Colloid Interface Sci. 44 (1973) 475.

[45] D.R. Rigsbee, P.L. Dubin, Langmuir 12 (1996) 1928.

[46] E.A. Sudbeck, P.L. Dubin, M.E. Curran, J. Skelton, J. Colloid Interface Sci. 142 (1991) 512.
[47] F. Tokiwa, K. Tujii, Bull. Chem. Soc. Jpn. 46 (1973) 2684.

[48] J. Kido, Y. Imamura, N. Muramoto, K. Nagai, J. Colloid Interface Sci. 150 (1992) 338.

[49] P.L. Dubin, S.S. Thé, L.M. Gan, C.H. Chew, Macromolecules 23 (1990) 2500.

[50] E.B. Abuin, J.C. Scaiano, J. Am. Chem. Soc. 106 (1984) 6274.

[51] M. Almgren, P. Hansson, E. Mukhtar, J. van Stam, Langmuir 8 (1992) 2405.

[52] F.M. Winnik, M.A. Winnik, S. Tazuke, J. Phys. Chem. 91 (1987) 594.

[53] Y. Hu, C. Zhao, M.A. Winnik, Langmuir 6 (1990) 880.

[54] J. Xia, P.L. Dubin, Y. Morishima, T. Sato, B.B. Muhoberac, Biopolymers 35 (1995) 411.

[55] K. Yoshida, Y. Morishima, P.L. Dubin, M. Misusaki, Macromolecules 30 (1997) 6208.

[56] Y. Morishima, Y. Tominaga, M. Kamachi, T. Okada, Y. Hirata, N. Mataga, J. Phys. Chem. 95 (1991) 6027.

[57] P. Mukerjee, J.R. Cardinal, J. Phys. Chem. 82 (1978) 1620.

[58] S.J. Rehfeld, J. Phys. Chem. 74 (1970) 117.

[59] S.J. Rehfeld, J. Phys. Chem. 75 (1971) 3905.

[60] Y. Morishima, Prog. Polym. Sci. 15 (1990) 949.

[61] K. Kalyanasundaram, J.K. Thomas, J. Am. Chem. Soc. 99 (1977) 2039.

[62] D.-Y. Chu, J.K. Thomas, Macromolecules 17 (1984) 2142.

[63] P. Lianos, R. Zana, J. Colloid Interface Sci. 84 (1981) 100.

[64] F.M. Winnik, H. Ringsdorf, J. Venzmer, Langmuir 7 (1991) 905.

[65] F.M. Winnik, H. Ringsdorf, J. Venzmer, Langmuir 7 (1991) 912.

[66] F.M. Winnik, S.T.A. Regismond, E.D. Goddard, Colloids Surfaces 100 (1996) 243.

[67] E.D. Goddard, P.S. Leung, Langmuir 8 (1992) 1499.

[68] P.L. Dubin, M.E.Y. Vea, M.A. Fallon, S.S. Thé, D.R. Rigsbee, L.M. Gan, Langmuir 6 (1990) 1422.

[69] P.L. Dubin, D. Davis, Colloids Surfaces 13 (1985) 113.

[70] N. Nishikido, J. Colloid Interface Sci. 120 (1987) 495. 